\title{
TI.36.1
}

\section{Multi-Factor Authentication (MFA) Interoperability Profile Working Group Final Report}

- PDF: MFAlnteropFinalReport-3.pdf

- Text: MFAInteropFinalReport-3.txt

More Information

\begin{tabular}{|l|l|}
\hline Repository ID & TI.36.1 \\
\hline Persistent URL & http://doi.org/10.26869/TI.36.1 \\
\hline Title & Multi-Factor Authentication (MFA) Interoperability Profile Working Group Final Report \\
\hline Authors & Karen Herrington, David Walker, Eric Goodman, Jim Jokl, Scott Cantor \\
\hline Sponsor & InCommon TAC \\
\hline Review & \\
\hline Status & Legacy \\
\hline Publish Date & $6 / 23 / 2016$ \\
\hline DOI & $10.26869 /$ TI.36.1 \\
\hline Signature & \\
\hline Deprecated & No \\
\hline Future Review & \\
\hline Supersedes & \\
\hline Format & PDF \\
\hline Related Docs & TI.37.1, TI.38.1, TI.39.1, TI.40.1, TI.41.1, TI.42.1 \\
\hline Development Location & \\
\hline IP Framework & \\
\hline Subject Tags & \\
\hline Notes & \\
\hline
\end{tabular}

